\title{
A Coleção Fotográfica V-8
}

Cássia Denise Gonçalves

Marli Marcondes

Centro de Memória - Unicamp (CMU)
RESUM 0 : Este artigo trata da coleção de fotografias históricas da cidade de Campinas e de seus personagens, acumulada pelo fotógrafo A ristides Pedro da Silva, conhecido como V-8. 0 estud o aborda a trajetória do fotóg rafo, as origens e composição do conjunto, a circulação das imagens em Campinas, a aquisição da coleção pela Unicamp/ Centro de M emória e ainda a sua organização e conservação.

PA LAVRAS-ChaVE: Coleção. Fotografia. Conservação. Documentação. C entro de M emória. Cidade.

ABSTRACT: This article is about the historical photos of $C$ ampinas city and its characters, shot by photographer Aristides Pedro da Silva, known as V-8. The study relates the paths taken by the photographer, the collection's sources and composition, the circulation of the images in C ampinas and the collection's purchase by Unicamp/ C entro de M emória (M emory C entre), in addition to its organisation and preservation.

KEYW O RDS: Collection. Photography. Conservation. Documentation. Centro de Memória. City.

N ota biográfica ${ }^{1}$

0 fotógrafo e colecionador de fotografias antigas Aristides Pedro da Silva, conhecido por V-8², nasceu em 1921 no Arraial dos Souzas, hoje distrito de Campinas, São Paulo, na Fazenda Atibaia. Sua mãe, Presciliana Silveira, trabalhava como empregada para as famílias da elite local. Seu pai, Benedito Pedro da Silva, era administrador de fazendas. 0 casal teve sete filhos.

Ainda menino, aos sete anos de idade, seus pais, a convite de 0 rozimbo $\mathrm{Maia}^{3}$, transferiram-se para a Fonte Sônia ${ }^{4}$, na Fazenda Cachoeira,
1. Os dados biográficos deV-8, bem como os de sua trajetória profissional, foram extraídos da obra Foto V8 (SCARPINETTI, 1999) e da entrevista concedida a Cássia D. Gonçalves (SILVA, 1998). Este texto também foi baseado em informações fornecidas durante os vários anos de convivência entre $\mathrm{V}-8$ e a equipe técnica do CMU.

2. 0 estranho apelido pertencia originalmente ao seu irmão, o qual, nos jogos de futebol, vestia um calção semeIhante a uma peça feminina, a calcinha (calção) tipo V-8. Quando 0 irmão mudou-se para outra cidade, Aristides já era conhecido como "o irmão doV-8".

3. Orozimbo Maia foi intendente municipal de Campinas entre 1891 e 1904 e prefeito da cidade de 1908 a 1932, ou seja, por pelo menos cinco mandatos. A Fazenda Cachoeira, de sua propriedade, era produtora de café. 
4. No início da década de 1920, descobriu-se que a água da fonte existente na Fazenda Cachoeira era radioativa.A Fonte Sônia foi instalada em 1921, para a comercialização do produto, e metade da sede da fazenda foi transformada em hotel. no município de Valinhos, e lá permaneceram até 1937, quando foram despedidos. A família então se mudou para Campinas onde sua mãe montou uma banca no M ercado M unicipal; e seu pai logo veio a falecer. Aristides tinha, na época, pouco mais de 16 anos.

Dos sete irmãos, ele foi o único que não estudou, ou melhor, estudou somente as primeiras letras. Seu primeiro trabalho fo i como entregador de leite na Leiteria Santana. Depois, trabalhou na Fundição G erin N eto. C hegou a abrir uma lavanderia, a Lavanderia V-8, na casa onde morou por quase toda a sua vida, na Rua Júlio Frank, no bairro do Botafogo, anos depois transformada em estúdio fotográfico.

A ristides ta mbém esteve envolvido com o futebol de Campinas, tendo sido técnico do juvenil do G uarani Futebol Clube por 10 anos, entre 1950 e 1960 .

$\mathrm{N}$ ão casou, não teve filhos. Morou com a mãe, na mesma casa, até ela falecer. Apesar de possuir amigos e gozar de certa popularidade na cidade, vivia só, recebendo esporadicamente a visita de sua irmã mais velha Beatriz, que vinha de São Paulo e hoje é falecida.

0 interesse de V-8 pela fotografia surgiu em função, principalmente, do seu desejo frustrado de pintar. 0 fotógrafo conta que era comum, na Fonte Sônia, os filhos dos colonos se aproximarem dos hóspedes, muitos deles estrangeiros. N uma dada ocasião, ele fez amizade com um casal de franceses que lá passava uma temporada. 0 francês, que pintava, costumava caminhar pela fazenda, e o menino o acompanhava carregando seus apetrechos de pintura. Essas saídas acabaram moldando o olhar do pequeno Aristides, despertando nele o interesse pelo desenho e pela pintura.

Às vezes, acontecia desses hóspedes adotarem algumas dessas crianças. Foi o que quase aconteceu com V-8. 0 casal de franceses se interessou em adotar o menino, que a princípio concordou, mas acabou desistindo de partir.

Q uando sua família veio morar em Campinas, em 1937, A ristides chegou a cursar, não por muito tempo, uma escola de pintura. Acabou, contudo, enveredando pelo caminho da fotografia, até mesmo como um meio de sobrevivência, transformando-a em uma profissão. Aprendeu o ofício e dele extraiu, além do seu sustento, a sua necessidade de representação do mundo.

Trajetória de uma fotografia

A utodidata, V-8 começou fo tografando partidas de futebol, por volta de 1947. Um amigo seu, M ário de 0 liveira, fotógrafo amador, ofereceu-se para lhe ensinar os primeiros procedimentos.

A partir desse aprendizado, buscou aprimorar-se. Passou a atuar profissionalmente por volta de 1952 e, em pouco tempo, montou seu estúdio 
fotográfico, o Fo to V-8, na Rua 13 de Maio, no Edifício Catedral. 0 estúdio teve outros endereços - Rua C onceição e Rua Dr. Q uirino - antes de se estabelecer na casa da Rua Júlio Frank.

Começou tirando fotos $3 \times 4 \mathrm{~cm}$. Com o tempo aperfeiçoou-se em retratos de casamento. $\mathrm{N}$ a época, segundo V-8, o "retrato de casamento" estava restrito a duas ou três chapas: a noiva sozinha, o noivo e a noiva e, às vezes, ambos com os padrinhos. N ão havia ainda a prática da reportagem, ou seja, dos registros fotográficos fora do estúdio - uma série com a chegada da noiva na igreja, a cerimônia, os noivos no carro, no jardim, cortando o bolo, com os familiares -, a qual, segundo ele, só seria introduzida na década de 1960. 0 álbum de casamento, com as fotografias características desse rito, torna r-se-ia sua especialidade.

Entre as décadas de 1950 e 1970 , paralela mente às suas atividades de fotógrafo comercial, V-8 realizou um importante trabalho de documentação das principais transforma ções urbanas verificadas na cidade de Campinas, decorrentes da implantação do Plano de Melhoramentos Urbanos ${ }^{5}$, de Prestes M aia, em 1932. Essas transforma ções foram efetivadas ma is intensamente a partir de 1950, com a demolição de edificações para a abertura de avenidas e vias expressas - sobretudo para a circulação de carros -, o desaparecimento de to do um casario antigo para dar lugar aos primeiros edifícios, a mudança no sistema do transporte urbano, etc (Figura 1).

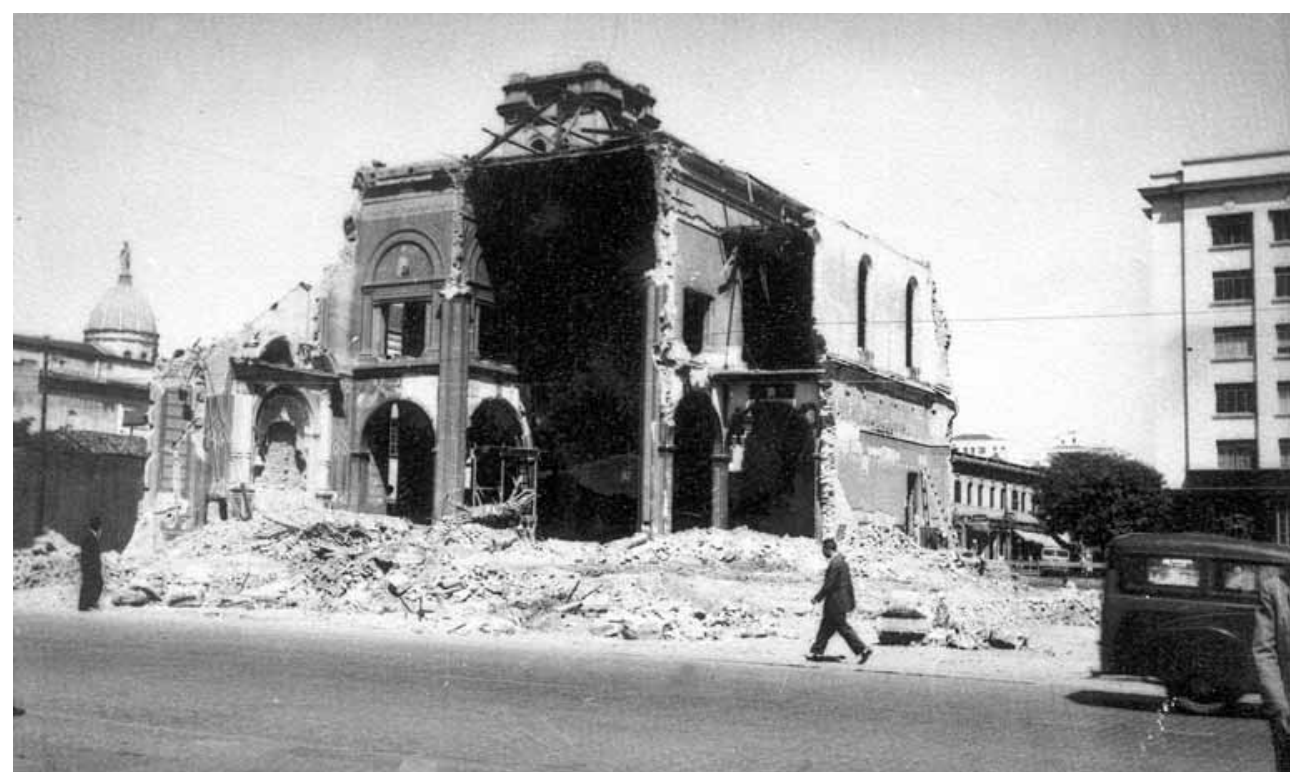

Figura 1 - Demolição da Igreja do Rosário. Campinas, SP, 1956, V-8. 
6. As informações sobre as séries fotográficas de V-8 foram fornecidas por Maria Helena de Campos, responsável pela catalogação da coleção.

7.Vanessa Proença explica que, com o alargamento das Ruas Campos Sales e Francisco Glicério, a Igreja do Rosário passou a ficar "no meio do caminho". Segundo o Plano Prestes Maia, a igreja deveria ceder lugar a uma praça (hoje Praça Guilherme), que formaria, em conjunto com o novo Palácio da Justiça, um centro cívico (PROENÇA, 2002, p. 32).

8. 0 Teatro Municipal Carlos Gomes foi inaugurado em 1930 e demolido em 1965. 0 edifício foi condenado por um laudo técnico que apontava a existência de fendas nas paredes e reentrâncias no piso do palco, apresentando perigo de desabamento. Foi demolido durante a administração do prefeito Rui Novais, a pedido do então secretário municipal de Obras eViação, Antônio Leite CarvaIhaes. 0 risco de desabamento do teatro foi contestado pelos contemporâneos que assistiram a demolição, inclusive por V-8. Hoje, no local encontrase uma loja da rede $C \& A$.
Esse trabalho de documentação se inicia, de modo sistemático, com o registro da construção do Estádio Brincos de 0 uro da Princesa, do G uarani Futebol Clube - desde o lançamento da sua pedra fundamental, em 1951, até sua inauguração, em 1953 -, bem como da demolição do estádio anterior. Porém, no fim dos anos 40, V-8 já havia registrado o começo das mudanças na paisagem urbana: o surgimento dos primeiros edifícios na região central da cidade ${ }^{6}$.

A primeira série das demolições é a da Igreja N ossa Senhora do Rosário (1956)7 , para o alargamento da Rua Francisco G licério. As séries ma is conhecidas são a da demolição do Tea tro M unicipal Carlos G omes (1964) - 0 Teatro M unicipal de Campinas ${ }^{8}$, como era conhecido - e a da despedida dos bondes em Campinas (1968).

Uma das últimas séries constituídas foi a do alargamento da Rua Aquidabã, aproximadamente em 1975, transformada em avenida e, num determinado trecho, em via expressa, saída para São Paulo. É curioso que V-8 identifique essa série como "demolição da Aquidabã".

A documentação produzida nessa época carrega a ambigüidade das transformações ocorridas em Campinas no período, pois se por um la do ela dá uma idéia de progresso e desenvolvimento, por outro revela o processo por meio do qual a cidade, para manter o seu crescimento acelerado, acabou abrindo mão da sua identidade.

Sobre a importância dessa documentação, o professor Lapa ${ }^{9}$, no pedido de auxílio à Fapesp para a compra da coleção, assinala:

Ao longo de uma vida, como fotógrafo profissional que é, Aristides Pedro da Silva, o V-8, foi sensível às grandes transformações urbanas pelas quais passou a cidade de $C$ ampinas, conseguindo flagrar muitas vezes o próprio a to de uma demolição ou construção de um espaço que é perdido, recuperado ou ganho, alterando a planta, a topografia, os símbolos e a própria identidade da cidade, [... numa etapa decisiva de sua história neste século, rumo a metropolização $0^{10}$.

Indagado, certa vez, sobre o sentido desse registro, V-8 respondeu que queria preservar o que estava "morrendo" na cidade. Assim, a sua fotografia documental caminha numa direção oposta ao olhar de Beatriz Bacher:

A cidade muda. A cidade que conhecemos muda a cada minuto. [...] Surpreendo-me com um espaço vazio ou um novo prédio, não estava lá da última vez [...]. M as sei o que estava antes? N ão. A ausência do que não me lembro, sua demolição e substituição, ou a reforma de uma fachada $[\ldots]$ me fez pensar que estava perdendo a cidade que nunca guardei (BACHER, 2004, p. 20).

A ristides também gostava de fotografar sedes de fazendas, carros de boi, enfim, a paisa gem rural, um imaginá rio pictó rico construído ainda na infância, na Fonte Sônia. Ele chegou a retratar as cidades históricas de M inas G erais, mais especificamente os casarões, como se refere à arquitetura colonial dessas cidades. Deseja voltar a M inas, cujas cidades estão mais próximas do seu ideal 
de natureza bucólica, e onde as pessoas, segundo o fotógrafo, são mais simples e cordiais que as da cidade grande.

Perseguind o a iluminação ideal para fotografar em ambientes externos, ele gostava de repetir que "fotografia é luz". De uma feita, contratou o ator Vado ${ }^{11}$ para realizar fotografias de "preto véio" e "escravo" numa fazenda da região.

Um pouco antes de parar com a fotografia, numa última fase, V-8 radicalizou e passou a retratar "naturezas mortas", em cor. Q uando exibia essas "naturezas" às pessoas, sempre reclamava dos laboratórios da cidade, que alteravam a sua coloração.

Vânia Carvalho, no seu estudo sobre a relação entre a fotografia e a pintura no século XIX, faz uma análise apropriada a essa fase de V-8:

Se os estudos de luminosidade na pintura têm relação com a descoberta fotográfica, esta, por sua vez, procura na outra um modelo temático e compositivo a fim de compartilhar a posição de obra de arte tradicionalmente concedida ao trabalho do pintor (CARVALH 0 , 1991, p. 208).

V-8 to ma a fotografia como arte não somente quando a relaciona com a pintura, depreendendo-se disso que ele está se referindo à observação direta da natureza, aos temas tra tados pela pintura, à composição da cena, à incidência da luz - "Você vê, desde quando segurava as telas, já vinha incluída a arte da fotografia" (SC ARPIN ETTI, 1999, p. 14)-, mas também quando considera que o bom fotógrafo é um virtuose, no sentido do domínio da técnica: "Prá abrir uma porta tinha que ser bom. [...] N ão é a ssim abrindo uma porta com 35 [...]. Q ue era tudo chapa, um serviço difícil, tinha que retocar. Tinha que ser artista mesmo" (SCARPIN ETTI, 1999, p. 18).

0 fotógrafo não incorporou na sua coleção as fotografias de "casarão de fazenda", "escravo", "preto véio" e "natureza morta". Pensava em comercializá-las como "quadros" - aliás, elas já possuíam um passe-partout impresso no papel fotográfico emoldurando o tema enfocado. Q uando ele exibia essas imagens, a firma va ma is do que indagava: "Vende, não vende?".

\section{A Coleção V-8}

A Coleção V-8, que hoje integra o acervo da Área de Iconografia do Centro de Memória - Unicamp (CMU), possui 4.500 imagens, entre fotografias e negativos flexíveis e de vidro, datadas de 1880 a 1970, a proximadamente, cobrindo, portanto, quase um século. É composta por dois conjuntos que, a pesar de se distinguirem na sua forma de a cumula çã o, completamse e interagem entre si. Um conjunto, citado no item anterior, é constituído pelo registro das principais transformações urbanas de Campinas, e o outro por fotografias antigas da cidade e de seus personagens, coletadas e reunidas por V-8 ao longo dos anos.
9. José Roberto do Amaral Lapa foi professor do Departamento de História do IFCH/ Unicamp e um dos fundadores do CMU, juntamente com outros professores do seu departamento.

10. Trecho da solicitação de auxílio para a compra da Coleção V-8, encaminhada pelo professor José Roberto do Amaral Lapa ao Programa de InfraEstrutura de Pesquisa - Fase IV da Fapesp, de 1998. Vale esclarecer que a Fapesp não possui uma rubrica para aquisição de fundos e coleções.

11. Vado ficou conhecido na cidade por sua performance do poema Navio Negreiro, de Castro Alves. Encarna, por assim dizer, 0 tipo humano "escravo". 
12. Ver nota 10.

13. Maria Luíza Pinto de Moura pertencia a uma das tradicionais famílias campineiras. Era bibliotecária do Centro de Ciências, Letras e Artes (CCLA) e pesquisadora da história de Campinas.

14. José de Castro Mendes era desenhista, aquarelista, crítico de arte e pesquisador da história de Campinas. É autor das obras Retratos da velha Campinas, Efemérides campineiras, Velhas fazendas paulistas e do suplemento especial do jornal Correio Popular, História de Campinas. (Esses dados foram extraídos de recortes de jornais pertencentes à Hemeroteca CMU).

15. O professor Ciro Exel Magro, filho do também professor $\mathrm{Hi}$ lário Pereira Magro Júnior, pertencia a uma família de educadores campineiros, proprietária da Escola Modelo e do primeiro jardim da infância da cidade. As imagens doadas levam a crer que a coleção de fotografias de Ciro Magro foi constituída por um fotógrafo amador, tendo em vista o grande número de retratos que ela possui, os quais V-8 denominou de "modelos fotográficos". De qualquer modo, são fotografias da família, dos amigos, de passeios, de reuniões, da Escola Modelo e de seus alunos, etc., geradas no âmbito da vida privada.
0 início dessa coleção remonta à abertura do primeiro estúdio, 0 Foto V-8, na Rua 13 de Maio. Em meados de 1954, Aristides ganhou duas fotografias antigas de Campinas e as colocou em exposição. Uma fo to trazia os primeiros carros que circularam na cidade, os fordecos; e a outra, a Rua Barão de Jaguara, uma das principa is ruas de comércio, ambas do início da década de 1930. A partir dessa iniciativa as pessoas se deram conta do interesse de V-8 e começaram a lhe repassar as fotografias antigas que possuíam.

Sobre a constituição da coleção, observa o professor Lapa no pedido de auxílio à Fapesp já mencionado르:

\begin{abstract}
Mas, mais do que o seu clic oportuno fixando o que se perderia em instantes ou se ganharia num outro átimo, foi também recolhendo fotos e negativos, esquecidos ou rejeitados, jogados fora como incômoda velharia. $\mathrm{N}$ a medida em que cada vez mais se identificou com essas fotos, ocupando com elas praticamente todas as dependências da casa em que viveu muitos anos com a mãe, na Rua Júlio Frank 187, e hoje vive sozinho, foi se tornando conhecido pela sua preocupação com as velhas imagens da cidade e aí passou também a ser procurado por famílias tradiciona is, persona lidades e instituições que foram legando àquele homem [...] os seus próprios a rquivos ima géticos.

0 resultado disso é ser hoje Aristides o proprietário do mais completo acervo de negativos e fotos [...] sobre Campinas de que se tem notícia [...].
\end{abstract}

Além de doações de fotografias esparsas, essa parte do acervo é composta por três outras coleções: a que foi entregue por M aria Luíza Pinto de Moura ${ }^{13}$, com fotografias que pertenceram a seu pai e a José de $C$ astro $M$ endes ${ }^{14}$, a coleção doada por C iro Exel $M$ a gro ${ }^{15}$ e a coleção de Heitor Paulino, proprietário da Casa Paulino, uma tipografia que comercializava fotos da cidade.

De um modo geral, trata-se de imagens de Campinas na primeira metade do século $X X$, quando a cidade, livre das epidemias ${ }^{16}$ de décadas anteriores, apresentava um apara to urbano inédito - a iluminação pública, os bondes elétricos, os primeiros carros (os fordes-de-bigode), as principais ruas de comércio, os transeuntes, as praças com seus jardins e chafarizes, signos de uma cidade que se modernizava rapidamente, sem perder, contudo, o encanto de uma cidade do interior (Figuras 2 e 3 ).

$\mathrm{N}$ esse sentido, aponta o filósofo francês Jean Baudrillard:

O objeto é assim, no seu sentido estrito, realmente um espelho: as imagens que devolve podem apenas se suceder sem se contradizer. É um espelho perfeito já que não emite imagens reais, mas aquelas desejadas (BAUDRILARD, 2000, p. 98).

Assim, o longo período coberto pela coleção deve-se ao fa to de que nela figuram tanto as fotografias coletadas e reunidas por V-8 ao longo dos anos como aquelas oriundas do seu trabalho documental. $0 \mathrm{~s}$ do is conjuntos seriam fundidos sob o selo Foto V-8 ${ }^{17}$, um modo de garantir uma unidade aos conjuntos e a autoria da coleção.

Camila Pinto, a o abordar a noção de coleção e de antigo na série fotográfica Campinas antiga, ressalta essa questão: "0 fa to de V-8 criar um selo identificador não só das imagens produzidas por ele, mas também das que 


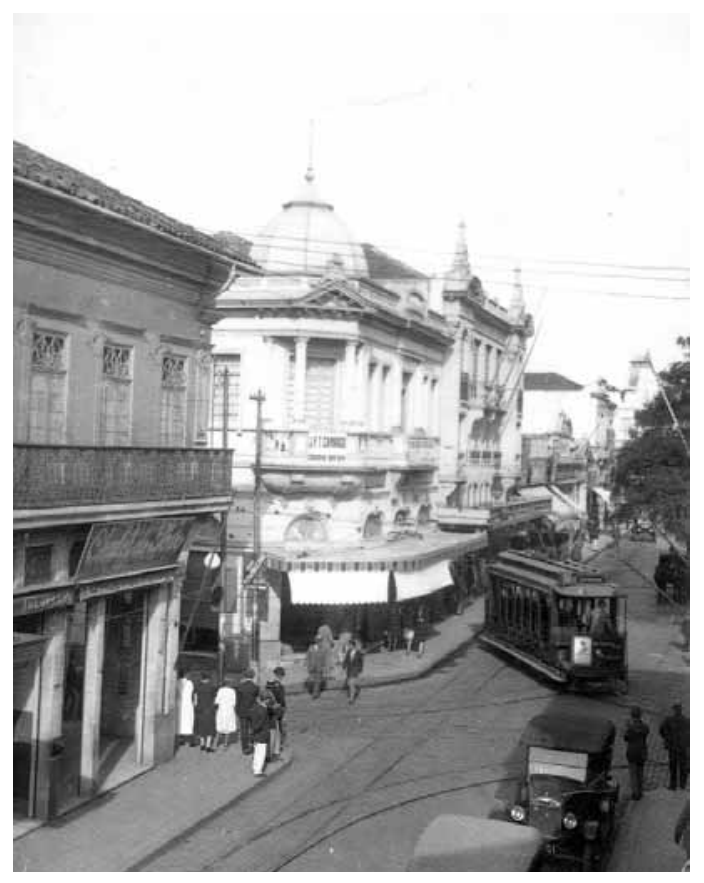

Figura 2 - Rua Barão de Jaguara com Rua General 0 sório. Campinas, SP, 1928.

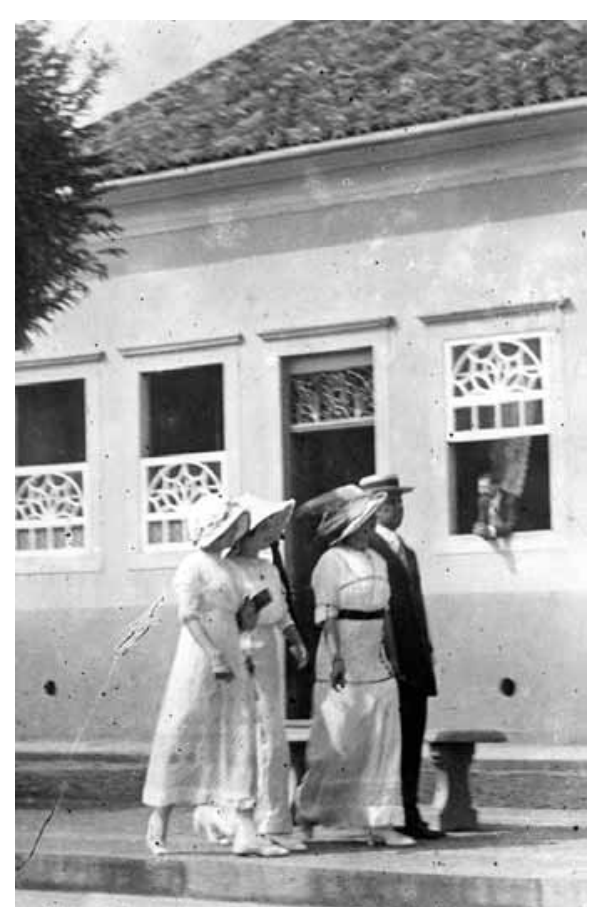

Figura 3 - Saída da missa da lgreja Matriz do Carmo. Campinas, SP, 191?.
16.As epidemias de febre amarela se abateram sobre a cidade a partir de 1889 e por toda a década de 1990, mais precisamente em 1890, 1892, 1896 e 1897 (LAPA, 1996). A febre foi responsável por um grande número de mortes, ocasionando o êxodo temporário de parte dos habitantes e a transferência de algumas casas comerciais e indústrias para outros centros. Normas de ocupação do espaço urbano e medidas sanitárias foram adotadas para a erradicação da febre, debelada oficialmente em 1897.

17. Voltaremos ao selo Foto $\mathrm{V}-8$ mais adiante, quando abordarmos o circuito de circulação da coleção em Campinas. 
18. Sobre a questão da autoria na Coleção V-8 ver PINTO, 2003. foram recolhidas ou a ele doadas durante a sua dupla trajetória de fotógrafo e colecionador, define uma noção de autoria [...]" (PIN TO , 2003, p. 3). Autoria da coleção que acaba extrapolando para a autoria das imagens ${ }^{18}$.

E será dessa maneira que elas passarão a circular na cidade, o que irá gerar certa confusão nas pessoas, sendo comum pergunta rem qua ntos anos tem V-8, a final de contas.

A circula ção das imagens

O s objetos antigos pa recem contra dizer as exigências do cálculo funcional para responder a um propósito de outra ordem: testemunho, lembrança, nostalgia, evasão.

(Jean Baudrillard)

Com o crescimento do acervo, o Foto V-8 to rnou-se também uma espécie de arquivo fotográfico da cidade, constituindo uma referência para a população. 0 fotóg ra fo explorou comercialmente as imagens, fornecendo cópias por um custo não muito a lto.

A circulação das ima gens em C a mpinas deu-se por meio da imprensa local e das exposições realizadas a pedido de instituições diversas e do poder público. Assim, destacam-se a exposição de fotografias Campinas antiga, que integrou as festivida des oficia is do bicentenário da cidade, em 1974, e a ma téria ta mbém chamada Campinas antiga, publicada na edição especial C ampinas 200 anos, do diário Correio Popular, de 26 de maio de 1974.

$\mathrm{N}$ a edição do jornal há uma chamada para a exposição:

$\mathrm{N}$ uma contribuição aos festejos do bicentenário de Campinas, o C O RREIO PO PULAR, numa promoção conjunta com a Prefeitura M unicipal de Campinas, realizará uma interessante exposição de fotografias de Campinas antiga, pertencentes a o a cervo do FO TO V-8, que conseguiu reunir fotos realmente preciosas, sob o ponto de vista histórico, e que certamente despertarão o mais vivo interesse de toda a cidade. Podemos adiantar que a maioria dessas fotos é inteiramente inédita, com sugestivos aspectos da velha C ampinas, suas ruas e praças, seus antigos e tradicionais edifícios, seus usos e costumes, suas personalidades ilustres, aspectos interessantes de uma cidade que se transformou e que se projeta como um centro econômico e cultural (PIN TO, 2003, p. 7-8).

A mesma edição do jornal, nas últimas páginas, traz um retra to de V-8 e um verbete que o identifica como proprietário das fotografias, enaltece 0 seu cuidado e carinho pelas "coisas da velha Campinas" e, ainda, faz a propaganda de dois álbuns fotográficos por ele organizados, como lembranças inesquecíveis do bicentenário.

Finalmente, na última página da edição, tem-se o binômio passado/ presente com a estampa de duas fotografias: uma vista parcial da cidade de 1870 , cujo destaque é a Matriz Nossa Senhora da Conceição 
rodeada por um baixo casario, e que leva o selo Fo to V-8 à esquerda da imagem, e uma vista a érea da região central da cidade, de 1974, já pa rcialmente toma da por edifícios.

Sobre a circulação dessas imagens, C a mila Pinto comenta: "[... ] é interessante notar que o uso público dessas fotografias de uma Campinas Antiga contribui para a formação de uma memória oficial da cidade ou própria do senso comum que identifica nas imagens um passado que se transforma em referência" (PIN TO, 2003, p. 4).

A presença da Coleção V-8 nas comemorações do bicentenário contribuiu para perpetuar uma determinada imagem de "antigo" para Campinas, forjando um passado mítico para os seus habitantes. Hoje, é comum ouvirmos as pessoas dizerem, diante de uma foto da coleção de V-8, que gostariam de ter vivido naquele tempo. Como bem observou Baudrillard:

Todo objeto antigo é belo simplesmente porque sobreviveu e devido a isso se torna o signo de uma via anterior. [...]. Hoje a civilização tecnicista nega a sabedoria dos anciões, mas se inclina diante da densidade das coisas velhas, cujo único valor acha-se selado e seguro (BAUDRIШARD, 2000, p. 91 ).

Imagens negociadas

Durante os anos em que dirigiu o CMU, o professor Lapa acalento u a idéia de integrar a Coleção V-8 a o acervo da instituição, visando, além da preservação da memória fotográfica de Campinas, a explorar o seu potencial como objeto de pesquisa. Conforme argumentou na já referida solicitação de recursos à Fapesp:

[...] a aquisição desse acervo de imagens se transformará, de imediato, [...] numa matriz de informações, pesquisas e estudos para dezenas de pesquisadores - estudantes e professores - que nas mais diferentes áreas do conhecimento - História, Geografia, Sociologia, Antropologia, Demografia, Arquitetura, Urbanismo etc. - hoje estão trabalhando sobre a região de Campinas ${ }^{19}$.

Foram vários contatos e visitas realizadas pelo professor Lapa e pela equipe técnica do CMU à casa de V-8 para negociar a compra da coleção. Considerando a sua idade a vançada, 0 fato de não possuir descendentes diretos, bem como a questão da segurança e da integridade do material, V-8, a princípio, sempre se manifestava disposto a vendê-la, mas nunca chegava a concluir essa idéia. Uma grande dificuldade nesse processo, que numa certa medida se to rnou um impasse, é que V-8 não sabia quanto pedir pela coleção, ou qual era o seu valor monetário. Depois de alguns anos ele concordou em receber duas pesquisadoras do M useu Paulista da USP para realizar o laudo técnico e a a valiação do conjunto. A pós criteriosa avaliação, procedida pelas pesquisadoras 
20. Ver nota 10.

21. Os professores envolvidos na compra da ColeçãoV-8 pertencem ao Instituto de $\mathrm{Fi}$ losofia e Ciências Humanas, ao Instituto de Artes, à Faculdade de Educação e à Faculdade de Engenharia $\mathrm{Ci}$ vil, Arquitetura e Urbanismo.

22. Projetos e monografias já desenvolvidos a partir da Coleção V-8: BRASI LEIRO, 2002; COSTA, 2002; PINTO, 2003; TREVISAN, 2002; PROENÇA, 2002; SCARPINETTI, 1999.

23. Fundo é "o conjunto de documentos produzidos e acumulados por determinada entidade pública ou privada, pessoa ou família no exercício de suas funções e atividades, guardando entre si relações orgânicas e que são preservados como prova ou testemunho legal e/ ou cultural, não devendo ser mesclados a documentos de outro conjunto gerado por outrainstituição"(BELLOTTO, 1991, p. 79).
Solange Ferraz de Lima e Vânia Carneiro de Carvalho, foi atribuído à coleção 0 valor de $R \$ 42.262,00$,

[...] dada a sua raridade, preservação, valor histórico, possibilidades de reprodução, bem como pelas imagens que contém, que vão de edifícios históricos a ruas e logradouros públicos, de personalidades e instituições que são marcos da história da cidade, de séries que permitem em seu sequenciamento acompanhar a evolução e as transformações ma is explícitas da cidade e dos seus equipamentos, mobiliário e personagens, datando as fotos mais antigas da década de $1870^{20}$.

Contudo, haveria de levar mais alguns anos para que a Coleção V-8 finalmente fosse adquirida pela Unicamp, em dezembro de 2001 , pelo valor que the foi atribuído. Essa aquisição envolveu a mobilização de vários professore ${ }^{21}$, com 0 objetivo de mostrar à universidade a importância e 0 alcance da documentação para os seus estudos e pesquisa ${ }^{22}$.

\section{Da organização}

Ao contrário dos arquivos, que são acumulados no decorrer de atividades e que possuem uma única fonte produtora, as coleções são constituídas a partir da reunião artificial de documentos que, não mantendo relação orgânica entre si, a presentam alguma característica comum (C AM A RG 0; BELO TTO, 1996, p. 17).

A definição a cima, presente no Dicionário de terminologia arquivística, não é ma is elaborada do que aquelas encontradas nos dicionários de língua portuguesa. Contudo, ela não dá conta de situar o documento no interior do conjunto do qual faz parte. E mais: se as coleções não são geradas no desempenho de funções, como o são os a rquivos, tampouco são reunidas de "maneira aleatória", como entende o senso comum.

Considerando que, do ponto de vista a rquivístico, "a coleção constitui a antítese do fundo"23 (RO USSEAU, 1998, p. 286), a orientação para a organização de tais conjuntos não poderia ser mais genérica, estando restrita a dois únicos critérios: cronológico e geográfico.

Contudo, as coleções fotográficas se distinguem não somente pela natureza dos seus objetos/ imagens, mas também porque possuem formas específicas de acumulação que irão definir seu perfil. 0 conservador português Luís Pavão ressalta essa especificidade de modo bastante apropriado nesta passagem:

Uma coleção pode resultar da paciente procura do colecionador ao longo de anos ou da pesquisa de um historiador ou crítico de arte sobre um tema ou época; pode resultar das recolhas de um geógrafo, de um biólogo ou antropólogo sobre o seu trabalho de investigação; pode ainda advir da acumulação de fotografias de uma família ao longo de gerações; ou pode ser 0 resultado do trabalho de um fotógrafo ou geração de fotógrafos. A coleção tem a chancela de seu criador (grifo nosso) (PAVÃO, 1997, p. 255). 
Pelo que foi até aqui exposto, percebemos que uma das características da Coleção V-8 é a diversidade na sua composição. A coleção inclui fotos coletadas por V-8 de autoria de outrem - fotos esparsas ou compondo outras coleções, originais ou reproduções - e fotos da sua própria autoria, das quais uma parte se encontra inserida na série Campinas antiga. Enfim, trata-se de um vasto universo que apenas começou a ser explorado.

Cabe notar, conforme observou Luís Pavão, que

não é qualquer a grupamento ou conjunto de fotografias que se pode considerar uma coleção de fotografias. À noção de coleção preside um intuito, que the confere uma unidade, um significado próprio, difícil de encontrar num aglomerado de fotografias. $\mathrm{C}$ ada elemento que integra uma coleção faz parte de um todo, ganha sentido individual e coletivo precisamente atra vés do conjunto. É a esta noção de um todo orgânico que podemos chamar coleção (PAVÃo, 1997, p. 255).

Desse modo, na organização da Coleção V-8, o C M U manteve a classifica ção temática ${ }^{24}$ dada originalmente por V-8 e seu assistente W anderley Zago, que o auxiliou nessa tarefa. Assim, buscou-se não apagar os traços da sua organicidade, traduzida no modo como ela foi acumulada, reunida, e, ainda, naquilo que foi intercambiável nessa reunião.

\section{Da conserva ção}

A conservação de coleções fotográficas é uma atividade que compreende duas vertentes. De um lado, a conservação da informação, e aí se inclui a tarefa de ordenação, identificação, datação e indexação das imagens com vistas à sua disponibilização ao público. Uma outra vertente visa à conservação do suporte fotográfico: a higienização, restauração para preservação, planificação e acondicionamento das fotos e seus negativos. Portanto, a o falarmos em conservação de fotografias devemos ter em mente to do o complexo de atividades que essa tarefa implica.

Isso posto, buscaremos, a seguir, traçar um breve panorama do está gio atual de tratamento da Coleção V-8, a dquirida em 2001 pelo C MU.

Faz-se premente, hoje, a necessidade de concluir o processamento da referida coleção, por se tratar de uma documentação bastante solicitada por pesquisadores e conter imagens capazes de desvendar particula ridades da história campineira. É portanto em Campinas, região de origem da coleção, que ela adquire seu verdadeiro significado e valor.

Ao longo de sua vida, V-8 experimentou transformações tecnológicas variadas no campo da fotografia, da câmera caixote da Agfa até uma moderna $\mathrm{N}$ ikon, passando pela popular Voigtländer. 0 s papéis ta mbém fora $\mathrm{m}$ sendo aprimorados. Enquanto novos produtos eram lançados no mercado, outros desa pa reciam. As películas a uto-infla má veis foram sendo, a os poucos, substituídas por processos mais seguros, como os acetatos e, posteriormente, o poliéster.
24. Classificação temática da ColeçãoV-8: Reproduções, Despedida dos Bondes, Sociedade Campineira, Escola Modelo, Fazenda Chapadão, Escola Técnica Bento Quirino, Jockey Club/Hipódromo, Fazenda Mato Dentro/Instituto Biológico, CampinasAntiga,Tiro de Guerra 176, Os Primeiros Carros, Igreja do Rosário (Demolição), Mercado Municipal/Solar dos Alves, Regatas/Sousas/Rio Atibaia, Aquidabã (Demolição), Hilário Magro/Modelos Fotográficos, Teatro Municipal (Demolição),VistaAérea/Campinas, Ciro Magro/Diversos e Diversos/Locais Indefinidos. 
25. A unidade relativa do ar "mede a quantidade de vapor de água que um determinado volume de ar contém por comparação com a máxima temperatura de vapor de água que esse mesmo volume de ar pode conter à mesma temperatura. É expressa na forma de uma percentagem, que vai de $0 \%$ a $100 \% "$ (PAVÃO, 1997, p. 201).

26. 0 processo foto gráfico consiste num "conjunto de procedimentos e processos químicos e fotoquímicos que conduzem à obtenção de uma fotografia. Cada fotografia foi produzida por um processo fotográfico, que é possível identificar e que determina a sua estrutura e materiais componentes" (PAVÃO, 1997, p. 25).
Portanto, o conjunto de documentos que compõe a Coleção V-8 apresenta grande diversidade no que diz respeito a os ma teria is fo tog ráficos utilizados, exigindo do conservador um a tento trabalho de identifica ção.

Durante os 50 anos em que Aristides Pedro da Silva compôs sua coleção, ela permaneceu acondicionada da forma mais conveniente e segura, sob a óptica do proprietário. o s negativos de vidro estiveram guardados sempre em envelopes de papel pardo, empilhados e dentro de caixas de papelão.

Apesar de inadequada, essa forma de acondicionamento manteve sob segurança preciosas imagens que muitos visitantes desejaram obter de V-8 como suvenir. Foi sua determinação, mantendo sempre os originais guardados e distantes dos curiosos, que garantiu sua permanência.

Todavia, as condições a mbienta is às quais a coleção esteve exposta por cerca de 40 anos (perío do em que V-8 residiu em seu último endereço, na Rua Júlio Frank, 187 ) não eram a quelas idea is preconiza das pelos conservadores de coleções fotográficas. M antida em um aposento em que a umidade relativa do ar (UR) chegava facilmente a $90 \%$, a coleção passou por toda espécie de deterioração provocada pelo excesso de umidade relativa do $a r^{25}$.

Além do fator umidade, a variação constante de temperatura e a falta de ventilação e de luz favoreceram a proliferação de fungos. A ristides parecia ter consciência da efemeridade desses materiais fotográficos, pois se dedicara por um longo tempo a reproduzir seus originais, ou seja, a criar cópias de segurança.

Q uando a coleção foi transferida para o CM U, dadas as condições em que se encontrava, fo i necessário colocá-la num ambiente intermediário, antes de se proceder a a condicionamento e guarda com controle ambiental. Essa medida foi muito importante, pois a coleção encontrava-se acomodada às condições climáticas do a mbiente em que permanecera por tantos anos. Sabese que uma mudança brusca de um microclima para outro pode ocasionarperdas irreparáveis para os materia is fotográficos, sobretudo para os negativos. A emulsão pode romper-se e descolar do suporte. $N$ os negativos em colódio podem ocorrer rachaduras, e os positivos de papel podem enrolar.

Assim, para evitar conseqüências gera Imente desastrosas, por cerca de um ano, a coleção foi mantida num ambiente mais seco e menos quente, a guardando tratamento. Recentemente vem sendo transferida para uma área adequada.

0 que se pôde observar na coleção, exposta às condições anteriormente descritas, foi a presença de fungos em muitos negativos, sobretudo na queles que estiveram mais sujeitos à umidade.

0 tratamento da coleção teve início a partir de uma avaliação sobre cada item, envolvendo uma a nálise sobre o processo fotográfico ${ }^{26}$ e 0 estado de conservação do material e uma proposta para o seu tratamento. É somente a partir da identificação do processo fotográfico que se pode avaliar o melhor método para o tratamento dos documentos.

N o caso da referida coleçã 0 , houve necessidade, também, de se adotar uma medida emergencial. Foram separados todos os negativos de vidro 
quebrados e/ ou trincados, para se evitar danos maiores ou ainda a perda de partes constituintes do suporte.

A a valiação do conjunto teve início a partir desses negativos de vidro, pois esse material a presentava sério comprometimento quanto à conservação. $A$ coleção é composta, essencialmente, de originais do fim do século XIX e início do XX. Há também uma grande quantidade de negativos de vidro de segunda geraçã 0 , assim como originais do mesmo material que datam das décadas de 1950 e 1960.

A té o momento não foram encontrados negativos produzidos em colódio, albumina ou em nitra to de celulose. Alguns exemplares de negativos no tom castanho-claro, que, aparentemente, se parecem com negativos em colódio, foram de fato produzidos em gelatina e receberam uma viragem (banho) de mercúrio. Essa prática era usual na correção de negativos subexpostos e fo i amplamente utilizada por V-8.

Todos os exemplares de negativos de vidro analisados possuem emulsão com brometo de prata disperso em gelatina. Seu esta do de conserva ção pode ser assim resumido:

a) alterações físicas: à exceção dos negativos de vidro produzidos nas décadas de 1950 e 1960 , os demais apresentam ranhuras na emulsão, suporte riscado, vidro trincado e/ ou quebrado e descolamento da emulsão nas bordas.

b) alterações químicas: existência de manchas ocasionadas por resíduos de produtos usados na fixação da imagem como o thiosulfato, oxidação e sulfuração, opacidade dos vidros mais antigos em conseqüência do processo de lixiviação.

c) alterações biológicas: presença de fungos.

A proposta de tratamento para os negativos de vidro compreendeu a sua higienização mecânica com pincel macio e com soprador, a limpeza do suporte com álcool et́lico diluído e a remoção de fungos com tricloroetano.

$\mathrm{N}$ em sempre é possível a remoção de fungos, sobretudo se já tiverem penetrado na emulsão. N esse caso, a emulsão torna-se frágil e pode separar-se do suporte. G rande parte dos negativos mais antigos da Coleção V-8 encontrase com razoável perda de emulsão nas bordas.

A tarefa mais delicada no tratamento da coleção tem sido a estabilização dos negativos de vidro quebrados, o que é feito deixando o negativo entre dois outros vidros de mesmo tamanho, selados por uma fita adesiva livre de acidez, a Filmoplast P-90.

A tenção especial vem sendo dada também aos numerosos negativos retocados. $\mathrm{N}$ a série fotográfica definida por V-8 como Hilário Magro/ Modelos fotográficos da época, um conjunto de retratos da eminente família Magro e de seus amigos e conhecidos, doado por Ciro Exel Magro, há alguns negativos retocados, cujo objetivo da intervenção era obter um efeito de pintura. N ão se sabe ainda se essas intervenções foram feitas por V-8 ou por um fotógrafo 
desconhecido. É certo, porém, que V-8 era apaixonado pela pintura e por isso buscava efeitos pictóricos em suas fotografias, não apenas na escolha da composição e iluminação, mas também no uso de máscaras e intervenções com pincel.

Portanto, foi necessário muito cuidado na higienização desses negativos para que não se removessem acidentalmente os retoques, parte integrante do documento (Figura 4 ).

Todo o conjunto de negativos de vidro da coleção, a inda em fase de tratamento, vem sendo acondicionado em envelopes em cruz, de papel neutro e de baixa gramatura, colocado num invólucro secundário (caixa), também de papel neutro, e finalmente depositado em arquivo de aço em área climatizada.

Um outro suporte bastante significativo na coleção são os negativos flexíveis, totalizando cerca de dois mil fotogramas. A higienização desse material não é tarefa fácil por causa da sensibilidade da película, vulnerá vel à abrasão. M esmo os pincéis mais macios podem riscá-los. Por possuírem gelatina nos dois lados do suporte, não é recomendado o uso de produtos úmidos sobre sua superfície. É conveniente apenas a utilização de pincel e soprador.

Já as imagens positivas sobre papel to talizam cerca de 500 unidades, em diferentes tamanhos. N ão há álbuns fotográficos, apenas uma pequena

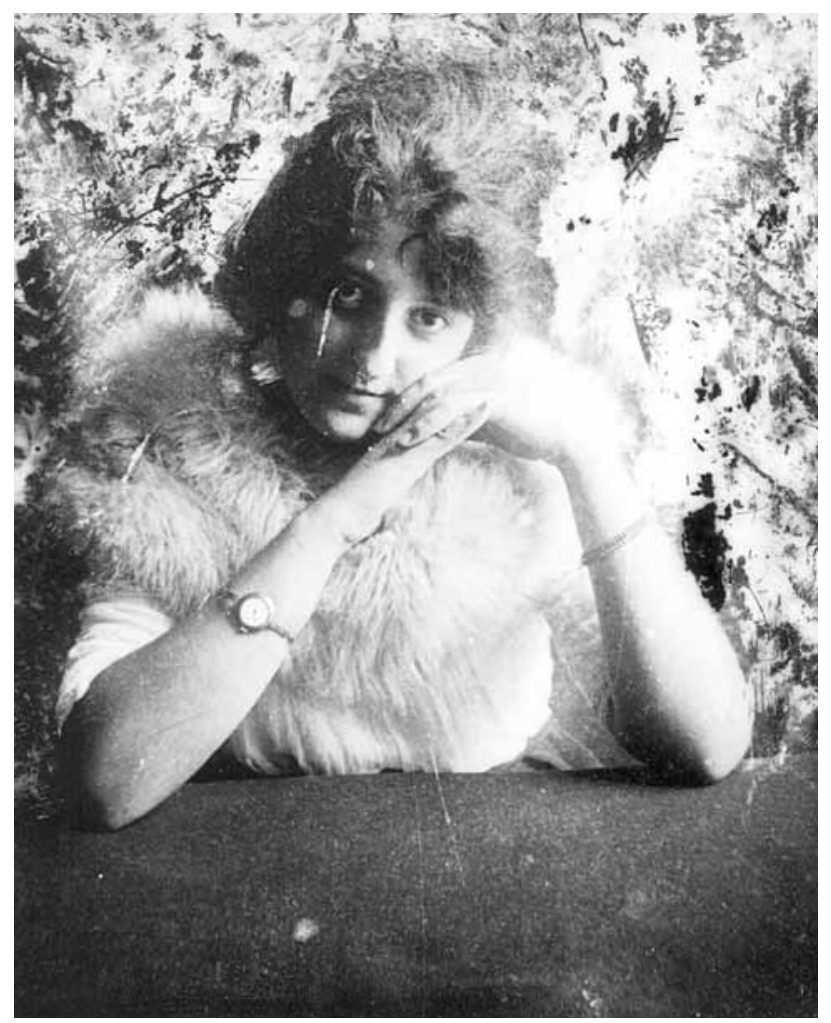

Figura 4 - Modelo Fotográfico. Campinas, SP, 1916. 
encadernação com reproduções comercializadas como álbuns. As ampliações são geralmente cópias recentes feitas a partir dos negativos flexíveis e/ ou de vid ro. Fo ra m la rga mente utiliza das em exp o sições fo to grá ficas, tendo sido coladas em cartão de alta gramatura. Por esse motivo, op tou-se por manter esses positivos nessas mesmas condições, pois a tentativa de descolamento poderia ocasionar perdas irrepa rá veis.

A higienização desse material é realizada com pincel macio e também com soprador. As fotografias rasgadas ou com dobras profundas são reparadas como uso de papel japonês. As tiras de papel japonês são rasgadas no tamanho da rachadura (e não cortadas com estilete), aplicadas no verso da fotografia no sentido da fissura e, depois, coladas com cola neutra (carboximetilcelulose). Cobre-se a fotografia com um pedaço de entretela e sobre ela aplica-se o mataborrão. Esse tipo de reparo dos positivos evita que nas proximidades da fissura a emulsão comece a se desprender do suporte.

A etapa seguinte consiste no acondicionamento primário das fotos em jaquetas de poliéster, com sustentação de cartão rígido e neutro. 0 acondicionamento secundário é feito em pastas suspensas, confeccionadas em cartão livre de acidez. Por último, acondiciona-se a documentação em área climatizada, mantendo-se ininterruptamente a UR a $45 \%$ e a temperatura a $20^{\circ} \mathrm{C}$.

$O$ s ma teria is a qui citados, ou seja, negativos de vidro, flexíveis e positivos de papel $P \& B$, são os mais comumente encontrados na coleção de Aristides Pedro da Silva. To do tratamento dado aos documentos vem sendo realizado no próprio C entro de M emória, no laboratório de conservação/ preservação de fotografias. À exceção das pastas suspensas, todas as embalagens também têm sido confeccionadas no CMU. Esse processo ocorre na medida em que a quantidade de material processado não excede a capacidade produtiva do setor. Ao contrário de instituições que recebem coleções da ordem de 10,20 e até 30 mil imagens, contamos com número bastante menor de documentos, o que nos favorece na a dequação e excelência no tratamento.

0 uso de material plástico como o poliéster justifica-se pelo fato de ele ser está vel quimicamente, não reagindo com a emulsão, e transparente, permitindo fácil visualização, a lém de ser bastante resistente. Contudo, se 0 ambiente em que a fotografia se encontra variar em umidade e temperatura pode ocorrer aderência da imagem ao poliéster. Recomenda-se, portanto, seu uso apenas em áreas com controle ambiental.

o CMU conta, a tualmente, com uma pequena sala climatizada, destinada apenas à guarda dos materia is fotográficos, depositados em um a rquivo deslizante de aço com pintura polimerizada. Mas a existência de uma sala climatizada não é garantia de eficiência na preservação dos documentos nela abrigados. É importante que haja uma conscientização de toda equipe sobre os cuidados ao se manusear o documento. A manipulação correta pode assegurar maior longevidade a material, sobretudo se associada aos cuidados com a higiene do local de trabalho e a proteção contra poluição. É também fundamental o cuidado com as instalações, garantindo-se a segurança contra incêndios, enchentes e sinistros. 
Parte da Coleção V-8 encontra-se digitalizada em alta resolução e armazenada em uma série de CD-RO M já devidamente a condicionada em área climatizada e disponível para o pesquisador. A partir de um índice temático manual, as imagens podem ser visualizadas no banco de imagens do CMU, em resolução de $W$ eb.

\section{REFERÊN CIAS}

BACHER, B. A cidade muda. Bravo!, São Paulo, v. 7, n. 82. jul. 2004, p. $20-21$.

BADARÓ, R. de S. C. Campinas: o despontar da modernidade. Campinas: Unicamp/CMU, 1996 (Campiniana, 7).

BAUDRILLARD, J. O sistema dos objetos. São Paulo: Perspectiva, 2000. (Debates).

BELLOTTO, H. L. Arquivos permanentes: tratamento documental. São Paulo: T.A. Queiroz, 1991.

CAMARGO, A. M. de A.; BELLOTTO, H. L. Dicionário de terminologia arquivística. São Paulo: AAB - Núcleo Regional São Paulo, 1996.

CARPINTERO, A. C. C . Momento de ruptura: as transformações no centro de Campinas na década dos cinqüenta. Campinas: Unicamp/CMU, 1996 (Campiniana, 8).

CARVALHO,V.C. de. A representação da natureza na pintura e na fotografia brasileiras do século XIX. In: FABRIS, A. (org.). Fotografia: usos e funções no século XIX. São Paulo: Edusp, 1991. p. 199-231 (Texto \& Arte, 3).

LAPA, J. R. do A. A cidade: os cantos e os antros: Campinas 1850-1900. São Paulo: Edusp, 1996.

LAVED RINE, B. La conservation des photographies. Paris: Presses du CNRS, 1990.

NEWHALL, B. The History of Photography:from 1839 to the Present. New York:The Museum of Modern Art, 2002.

PAVÃO, L. Conservação de coleções de fotografia. Lisboa: Dinalivro, 1997.

PIRES, M. Valinhos tempo e espaço. Campinas:Academia Campinense de Letras, n. 37, 1978.

REILLY, J. M. Care and Identification of $19^{\text {th }}$. Century Photographic Prints. Rochester: Eastman Kodak, 2001. (Kodak Publication, n. G-2S).

ROUSSEAU, J.-Y.; COUTURE, C. Os fundamentos da disciplina arquivística. Lisboa: Publicações Dom Quixote, 1998. (Nova Enciclopédia, 56). 


\section{Hemeroteca}

CAMPINAS 200 anos. Correio Popular, Campinas, 14 jul. 1974.

RODRIGUES, A. S. Orozimbo Maia, grandeza e poder de personalidade. Correio Popular, Campinas, 14 abr. 1967.

TEATRO MUNICIPAL de Campinas teve vida curta: apenas 35 anos. Folha de S. Paulo, São Paulo, 12 set. 1965.

\section{Projetos e monografias}

BRASILEIRO, A. de F. O mercado municipal de Campinas enquanto local de convivência: análise a partir do acervo do fotógrafo V-8. Campinas, 2002.14 p. (Projeto de iniciação científica Pibic /Cnpq).

COSTA, E. A. As rupturas urbanas de Campinas através da fotografia de Aristides Pedro da Silva. Campinas, abr. 2002. 13 p. (Projeto de iniciação científica Pibic /Cnpq).

PINTO, C.A. A noção de coleção e de antigo na série Campinas Antiga deV-8. Campinas, SP, 2002. 7p. (Projeto de iniciação científica Pibic /Cnpq).

. A noção de coleção e de antigo na série Campinas Antiga deV-8. Campinas, SP, 2003. 25p. (Relatório parcial das atividades de iniciação científica Pibic /Cnpq).

. A noção de coleção e de antigo na série Campinas Antiga deV-8. Campinas, jul. 2003. 20p. (Relatório final das atividades de iniciação científica Pibic /Cnpq).

PRO ENÇA,V. A. T. Imagens da perda:a demolição da Igreja do Rosário registrada pelo fotógrafo V-8. Campinas, 2002.63 f. Monografia - Instituto de Filosofia e Ciências Humanas, Universidade Estadual de Campinas, Campinas, 2002.

SCARPINETTI,A. J. Foto V-8. Campinas, CMU, 25 jan. 1999. 37 p. (Trabalho final para a disciplina de História Oral).

TREVISAN, F. Teatro Municipal "Carlos Gomes": registros de sua história e sua demolição. Campinas, abr. 2002. 8 p. (Projeto de iniciação científica Pibic /Cnpq).

\section{Entrevista}

SI LVA, A. P. da. Aristides Pedro da Silva V-8: depoimento. Campinas, 1998 (concedida a Cássia Denise Gonçalves).

Artigo apresentado em 09/2004. A provado em 10/2004. 